\title{
INTELIGÊNCIA EMOCIONAL E ENGAJAMENTO NO AMBIENTE DE TRABALHO: ESTUDO EMPÍRICO A PARTIR DE TRABALHADORES GAÚCHOS
}

EMOTIONAL INTELLIGENCE AND ENGAGEMENT IN WORKPLACE: EMPIRICAL STUDY ON WORKERS FROM STATE OF RIO GRANDE DO SUL

ROGÉRIO HANSEN ${ }^{1}$

ADRIANE FABRICIO ${ }^{2}$

LIANE BEATRIZ ROTILI ${ }^{3}$

LUIS FELIPE DIAS LOPES 4

RESUMO: O objetivo deste artigo é identificar possíveis relações entre as dimensões de inteligência emocional e dimensões de engajamento no trabalho em trabalhadores gaúchos. Trata-se de uma pesquisa descritiva tipo survey, com abordagem qualitativa e quantitativa dos dados. Os participantes do estudo são 132 profissionais, que ocupam cargos de gestão ou são membros de equipes, que possuem atividade formal de trabalho remunerada, e atuam no estado do Rio Grande do Sul. Os instrumentos de pesquisa aplicados foram o Emotional Intelligence Appraisal ${ }^{\circledR}(\mathrm{EIA})$, questionário elaborado por Travis Bradberry e Jean Greaves (2016) e o Utrecht Work Engagement Scale (UWES-17) elaborado por Schaufeli e Bakker (2003) e adaptado por Angst, Benevides-Pereira e Porto Martins (2009). Identificouse que os profissionais gestores e membros de equipes possuem altos níveis de inteligência emocional $(77,27 \%)$ e engajamento no trabalho $(67,33 \%)$. Existe relação forte e positiva entre as dimensões de inteligência emocional e engajamento no trabalho $(0,613)$, ou seja, quanto mais índices de inteligência emocional o profissional apresentar, maior será o seu engajamento em relação ao seu trabalho. As evidências contribuem para as decisões organizacionais que implicam nos objetivos das organizações.

Palavras-chave: Inteligência emocional. Engajamento no trabalho. Gestão

ABSTRACT: The objective of this study is to identify possible relationships between the dimensions of emotional intelligence and dimensions of work engagement in southern Brasilian workers. It is a descriptive research type survey, with qualitative and quantitative approach of the data. The participants of the study are 132 professional managers and members of teams that have formal paid work and work in the state of Rio Grande do Sul. The applied research tools were the Emotional Intelligence Appraisal ${ }^{\circledR}$ (EIA) questionnaire developed by Travis Bradberry and Jean Greaves (2016) and the Utrecht Work Engagement Scale (UWES-17) prepared by Schaufeli and Bakker (2003) and adapted by Angst BenevidesPereira and Porto Martins (2009). It was identified that professional managers and team members have high levels of emotional intelligence (77.27\%) and work engagement (67.33\%). There is a strong and positive relationship between the dimensions of emotional

\footnotetext{
Data de submissão: 22/09/2017 Data de aceite: 02/09/2018 Data de publicação: 18/09/2018 1 Bacharel em Administração - DACEC/UNIJUÍ

2 Doutoranda em Administração PPGA/UFSM. Docente DACEC/UNIJUÍ

3 Mestranda em Desenvolvimento Regional - PPGDES/UNIJUIBolsista PROSUP/Capes Pesquisadora dos Grupos: GPCET - PPGA/UFSM e GEPOG PPGDES/UNIJUIBacharel em Administração - DACEC/UNIJUI

4 Professor Associado 4 do Departamento de Ciências Administrativas (DCA/UFSM)
}

RGO REVISTA GESTÃO ORGANIZACIONAL | VOL 11 - № 1 - JAN./ABR. - 2018 
intelligence and engagement at work $(0,61309)$, that is, the more indexes of emotional intelligence the professional presents, the greater will be their engagement in relation to their work. The evidence contributes to the organizational decisions that imply the goals of organizations.

Keywords: Emotional intelligence. Work engagement. Management

\section{INTRODUÇÃO}

Diante do desafio cada vez maior em gerir e liderar equipes multidisciplinares, multifocadas e diversificadas, a inteligência emocional se destaca como aspecto de competência inerente aos gestores, líderes e membros de equipes, como opção pela busca da qualidade de vida e engajamento no ambiente de trabalho. A inteligência emocional envolve a capacidade de perceber acuradamente, de avaliar e de expressar emoções; a capacidade de perceber e/ou gerar sentimentos quando eles facilitam o pensamento; a capacidade de compreender a emoção e o conhecimento emocional; e a capacidade de controlar emoções para promover o crescimento emocional e intelectual (MAYER; SALOVEY, 1997)

No final dos anos 90, Martin Seligman, então presidente da American Psychological Association, lançou diversos artigos que demonstravam a necessidade de mudança no foco das contribuições da Psicologia iniciando um movimento denominado psicologia positiva, que visa oferecer uma nova abordagem às potencialidades e virtudes humanas, estudando as condições e processos que contribuem para a prosperidade dos indivíduos e comunidades onde estão inseridos. Estes artigos apresentam e discutem essa nova proposta científica, que busca a melhoria da qualidade de vida dos indivíduos prevenindo patologias, transformando velhas questões em novas possibilidades de compreensão de fenômenos psicológicos como felicidade, otimismo, altruísmo, esperança, alegria, satisfação e outros temas humanos, tão importantes para a pesquisa quanto depressão, ansiedade, angústia e agressividade (SELIGMAN, 2001).

Nas organizações, o cultivo das emoções positivas promove uma disposição mental expansiva, tolerante e criativa, deixando as pessoas abertas a novas ideias e experiências. Por isso, muitos gestores sentem-se desafiados a realizar uma gestão baseada nos princípios da psicologia positiva, cientes de que a promoção da felicidade no ambiente de trabalho pode, além de atrair e reter talentos para equipe, transformar-se numa poderosa fonte de vantagem competitiva. Porém, como aderir aos princípios da positividade em um cenário corporativo cada vez mais complexo, pautado pela necessidade diária de superação de metas e objetivos, onde a cobrança, o estresse e os conflitos são presentes e constante.

É neste contexto que a inteligência emocional e o engajamento no trabalho são abordados e discutidos. Sendo a inteligência emocional definida como a capacidade de sentir, entender, controlar e modificar o próprio estado emocional ou o de outras pessoas. 0 termo se tornou famoso após o lançamento do best-seller Inteligência Emocional, de Daniel Goleman em 1995, após o lançamento desse livro, o termo foi rapidamente disseminado em diversos segmentos da sociedade (GOLEMAN, 1995; ROBERTS; FLORES-MENDOZA; NASCIMENTO, 2002).

O engajamento no trabalho proporciona emoções positivas, a pessoa se sente feliz, alegre, energizada, otimista e autoconfiante, estar engajado no trabalho faz com que a 
pessoa se sinta bem, e estando bem-humorada sente que a atividade no trabalho não é difícil, este estado influência também positivamente a sua criatividade e capacidade de solução de problemas. A boa saúde também está associado a pessoa engajada, pois sofrem menos de acometimentos psicossomáticos e físicos, como dores de cabeça, preocupações, tensão muscular. (SCHAUFELI; DIJKSTRA; VASQUEZ, 2013).

A inteligência emocional de gestores e membros de equipe, assim como a sua ligação com o engajamento no trabalho é um tema que de certo modo sofre resistências por grande parte dos profissionais da gestão, uma vez que a sua abordagem por muito tempo ficou limitada as áreas da psicologia e de alguma forma aos responsáveis pela gestão de pessoas nas organizações. Desde modo, os gestores passam a desempenhar cada vez mais o papel de mentores dos seus subordinados, tendo que de certa forma trabalhar em uma gestão de pessoas humanizada e personalizada. Os desafios do mundo moderno, colocam esta posição, de líder, em xeque, onde as competências de inteligência emocional do gestor e membros de uma determinada equipe é a mola propulsora para o engajamento e consequentemente para a melhora na qualidade de vida nas organizações.

Neste contexto este estudo tem como objetivo identificar possíveis relações entre as dimensões de inteligência emocional e de engajamento no trabalho em gestores e membros de equipe, que atuem com atividade remunerada no Estado do Rio Grande do Sul. Busca-se verificar a incidência da autoconsciência, autogestão, automotivação, empatia e habilidade social no trabalho, as quais operam como dimensões da inteligência emocional, e a incidência do vigor, dedicação e absorção, as quais operam como dimensões do engajamento. Na sequência, busca-se identificar a relação entre ambos os fenômenos.

Os fenômenos são considerados relevantes para o estudo tendo em vista que o modo com que as pessoas veem o trabalho na atualidade está se transformando, assim como as mudanças organizacionais e sociais. Neste sentido Schaufeli, Dijkstra e Vazquez (2003) explicam que os trabalhadores estão buscando cada vez mais autodesenvolvimento, ação cooperativa e envolvimento em atividades prazerosas e de realização pessoal, a partir desta visão o termo engajamento no trabalho surge para descrever as pessoas que sentem prazer em suas atividades de trabalho. Nesta mesma perspectiva, Salovey e Mayer (1990) confirmam que o uso correto das emoções possibilita ao indivíduo elaborar com maior habilidade planos para o futuro, ter pensamentos criativos, ser capaz de dosar e direcionar sua atenção e seu bom humor e, ao mesmo tempo, motivar-se, persistindo, mesmo diante de dificuldades, em seus propósitos anteriormente estabelecidos.

O presente artigo se estabelece em quatro partes, inicialmente é apresentada a revisão bibliográfica sobre inteligência emocional e engajamento no trabalho, na sequência apresenta-se a metodologia, a análise dos resultados e por fim as conclusões do estudo.

\section{REFERENCIAL TEÓRICO}

\section{Inteligência Emocional}

O conceito de inteligência emocional foi apresentado à comunidade científica pelos psicólogos Salovey e Mayer (1990, p. 189), em um artigo teórico, sendo definida como "a capacidade de o indivíduo monitorar os sentimentos e as emoções dos outros e os seus, de discriminá-los e de utilizar essa informação para guiar o próprio pensamento e as ações". 
O termo se tornou famoso após o lançamento do best-seller Inteligência Emocional, de Daniel Goleman em 1995, após o lançamento desse livro, o termo foi rapidamente disseminado em diversos segmentos da sociedade (GOLEMAN, 1995; ROBERTS, FLORESMENDOZA e NASCIMENTO, 2002).

Bradberry e Greaves (2016, p.7) definem que a trajetória física da inteligência emocional começa no cérebro, na medula espinhal. Os sentidos primários entram por aí e devem viajar até a parte frontal do nosso cérebro antes de podermos pensar racionalmente sobre a nossa experiência. Mas primeiro elas passam pelo sistema límbico, onde as emoções são sentidas. A inteligência emocional requer uma boa comunicação entre o cérebro racional e o centro emocional do cérebro.

O conceito de inteligência emocional pauta-se em cinco habilidades básicas e interdependentes denominadas por autoconsciência, autogestão, automotivação, empatia e habilidade social. As três primeiras referem-se a exames de reações do eu e ao que o indivíduo faz com seus próprios sentimentos, enquanto que as duas últimas se voltam para fora, em direção aos sentimentos dos outros e às interações sociais (GOLEMAN, 1995).

A autoconsciência é o primeiro componente da inteligência emocional. A autoconsciência significa uma compreensão profunda das próprias emoções, forças fraquezas, necessidades e impulsos. As pessoas com autoconsciência forte não são nem críticas demais nem irrealisticamente esperançosas. Pelo contrário, são honestas consigo e com os outros. Pessoas com alto nível de autoconsciência reconhecem como os seus sentimentos afetam a elas, as outras pessoas e seu desempenho profissional. A autoconsciência também está ligada a compreensão que as pessoas têm de seus próprios valores e metas (GOLEMAN, 2015, P.14).

Decorrente da autoconsciência, a autogestão agrega competências como autocontrole, transparência, adaptabilidade, superação, iniciativa e otimismo. Nenhum líder pode encarar emoções negativas, como raiva, pânico, ansiedade ou frustração, porque as emoções são contagiantes, especialmente as provenientes dos líderes. Esses não poderão ser eficazes no gerenciamento de pessoas se não adquirirem a habilidade de lidar com as próprias emoções (GOLEMAN, 1999).

A autogestão é o gerenciamento controlado dos nossos próprios impulsos e emoções, o qual "nos proporciona a clareza mental e a energia concentrada exigidas pela liderança", e impede que as emoções destrutivas nos tirem do rumo. Desta forma, "os líderes que permanecem otimistas e com uma atitude construtiva, mesmo sob intensa pressão, irradiam os sentimentos positivos responsáveis pela criação da ressonância" (GOLEMAN; BOYATZIS; MCKEE, 2002, p. 46-47).

Para Goleman (2002) o líder capaz de gerenciar suas emoções possibilita trabalhar melhor as emoções dos seus subordinados; acompanhar as mudanças do mundo do trabalho e fazer com que a organização se adapte as mudanças. A transparência, a integridade, são valores em que o líder que pratica a autogestão tem que ter, pois passa uma imagem de confiança e é também uma vantagem organizacional.

O termo motivação provém da palavra latina movere, que significa deslocar-se. Automotivação é a capacidade de se deslocar e não se deixar "levar". De um modo geral, motivo é tudo aquilo que impulsiona a pessoa a agir de determinada forma ou, pelo menos que dá origem a uma propensão, a um comportamento específico. A automotivação manifesta-se quando, o indivíduo acha que, faz sentido para enfrentar qualquer situação independentemente da dificuldade que esta apresente. Auto motivar-se implica controle de impulsos, o otimismo e a esperança e o chamado "estado de fluxo" (BRANCO, 2004). 
Goleman (1999, p. 324), ao expor a sua adaptação as cinco competências emocionais e sociais, define motivação, como saber "usar as nossas preferências mais profundas, para avançar e nos guiar para os nossos objetivos, nos ajudando a tomar a iniciativa e ser altamente eficientes para perseverar face a contrariedades e frustrações".

A competência da inteligência emocional que mais se identifica com o líder visionário é a empatia, pois a capacidade de compreender suas opiniões, ponto de vista e identificar os sentimentos permite que o líder tenha uma visão inspiradora. O líder que não consegue compreender seus subordinados será incapaz de inspirá-los. (GOLEMAN, 2002)

Em suas contribuições Bradberry e Greaves (2016, p.31) denominam a empatia como "consciência social", definindo-a como uma habilidade básica. "A consciência social é a nossa capacidade de reconhecer as emoções outros e saber o que de fato está se passando com as pessoas. Em geral, isso implica em perceber o que os outros estão pensando e sentido, mesmo quando não concordamos com eles"

A empatia é muitas vezes considerada como uma das competências subjacentes ao conceito da inteligência emocional, aplicando-se não só na esfera individual, como também ao grupo. Também ser vista como a base que permite que se criem relações num grupo, bem como pode ser encarada como um impulso das relações do grupo para o exterior (GOLEMAN; BOYATZIS; MCKEE, 2002).

A empatia no contexto do trabalho não implica adotar as emoções alheias, mas sim dar importância aos sentimentos dos liderados, e tomá-los em consideração para uma tomada de decisões eficaz (inclusive do ponto de vista emocional). Se as emoções forem expressadas de forma apropriada, os líderes serão capazes de captar sentimentos alheios, consolidando assim um sistema de orientação emocional. A empatia assume um papel imprescindível na eficácia social da vida profissional (GOLEMAN; BOYATZIS; MCKEE, 2002).

Pessoas com habilidade social tendem a ter um amplo ciclo de conhecidos e têm um dom para chegar a um denominador comum com pessoas de todos os tipos - um dom para desenvolver afinidades. Isso não significa que tenham contatos sociais constantes. Significa que atuam seguindo o pressuposto que sozinho não se realiza nada importante. A habilidade social é a culminância das outras dimensões da inteligência emocional. As pessoas tendem a ser bem eficazes em gerir relacionamentos quando conseguem entender e controlar suas próprias emoções e conseguem ser empáticos com os sentimentos dos outros (GOLEMAN, 2015, P.23)

Segundo Del Prette e Del Prette, (2001, p.57) os novos paradigmas organizacionais que orientam a reestruturação produtiva têm priorizado processos de trabalho que remetem, diretamente à natureza e à qualidade das relações interpessoais. Para Goleman (2012, p.136) "enviamos sinais emocionais sempre que interagimos, e estes sinais afetam aqueles com quem estamos. Quanto mais hábeis somos nas relações que mantemos com o outro, melhor controlamos os sinais que enviamos".

Portella (2005) sugere de forma sintética, que existem seis habilidades sociais principais: capacidade empática, capacidade reforçadora, auto apresentação positiva, assertividade, sensibilidade perceptiva e flexibilidade comportamental, ressaltando que os indivíduos competentes socialmente, ou seja, aqueles que conseguem otimizar as respostas sociais aos seus comportamentos, não são fortes em apenas uma ou duas habilidades sociais, mas têm bom desempenho na maioria delas.

A gestão de relacionamentos, a última das competências da inteligência emocional, inclui as capacidades de se comunicar de forma clara e convincente, desarmar conflitos e 
desenvolver laços pessoais fortes. Líderes ressoantes usam essas habilidades para disseminar seu entusiasmo e resolver desacordos, muitas vezes com humor e gentileza (GOLEMAN, 2015).

\section{Engajamento no Ambiente de Trabalho}

O tema surgiu na psicologia do trabalho e na literatura da área de gestão na década de 1990, seguindo uma tendência geral na direção dos estudos dos construtos sobre comportamentos organizacionais positivos (SCHAUFELLI; BAKKER, 2004). Partindo dos estudos relacionados a fatores negativos do trabalho, como a Síndrome de Burnout, que é relacionada ao agravamento do estresse e ao esgotamento no trabalho, a psicologia positiva procurou então evidenciar quais seriam os aspectos inversos a este fenômeno.

Com relação aos estudos empíricos do engajamento no trabalho, eles são recentes e a primeira pessoa que o conceituou academicamente foi Willian A. Kahn, em 1990, no artigo intitulado psychological conditions of personal engagement and disengagement at work. No mesmo artigo, o autor também referenciou o conceito oposto, o desengajamento (ausência de engajamento no trabalho) (KAHN, 1990). Este autor introduziu o conceito de engajamento e desengajamento pessoal. $O$ engajamento e o desengajamento no trabalho são comportamentos pelos quais as pessoas trazem ou deixam seus "eus", durante o desempenho das tarefas.

O reconhecimento destas características é importante especialmente para identificar aspectos positivos e o que se pode desenvolver como pontos fortes. Uma pessoa engajada percebe quando está inspirada ao identificar que sente prazer nas atividades que realiza e, consequentemente, seu trabalho é realizado de tal modo que ela e a organização são beneficiadas em algum nível. Reconhecer a carência desse engajamento é tão importante para a pessoa quanto para a equipe em que está inserida e a organização onde atua, e este reconhecimento é necessário para que a organização aja e faça com que as pessoas possam se sentir inspiradas e entusiasmadas no trabalho novamente (SCHAUFELI; DIJKSTRA; VASQUEZ, 2013).

Para Salanova e Schaufeli (2009) o engajamento trata-se de um estado positivo que possibilita e facilita o uso dos recursos, estando intimamente ligado ao desenvolvimento da organização, estimulando os resultados organizacionais positivos e, assim, reduzindo os negativos.

Bakker e Leiter (2010) definem engajamento no trabalho como algo positivo, que está relacionado ao bem-estar ou a uma satisfação caracterizada por um alto nível de energia e uma forte identificação com o próprio trabalho. De forma resumida, Hallberg e Schaufeli (2006) ilustram o engajamento com as atividades de trabalho como um estado de completa energia e dedicação à realização de uma função, estando dividido em três dimensões: vigor, dedicação e absorção.

Engajamento é um estado positivo da mente, realizador e relacionado ao trabalho que é caracterizado pelo vigor, dedicação e absorção. Mais do que um estado momentâneo e específico, o engajamento refere-se a um estado mais persistente e afetivo-cognitivo que não é focado em um objeto, evento, indivíduo ou comportamento específico trabalho (SHAUFELI; BAKKER, 2003).

Para Bakker e Demerouti (2008), o engajamento no trabalho está relacionado a um estado mental caracterizado por três dimensões fundamentais: vigor, que corresponde a altos níveis de energia e resiliência mental no trabalho; dedicação, que se refere a estar-se profundamente envolvido no trabalho, experimentando uma forte sensação de significado, 
entusiasmo e desafio; e absorção, que indica alto nível de concentração, onde o tempo passa rapidamente no ambiente de trabalho.

Segundo Shaufeli e Bakker (2003) o vigor caracteriza-se pelos altos níveis de energia e resiliência mental enquanto trabalha, vontade de investir no trabalho, e persistência em situações de dificuldade. A dedicação refere-se a estar fortemente envolvido em seu trabalho e experienciar um senso de significância, entusiasmo inspiração, orgulho e desafio. Absorção é caracterizada como estar completamente concentrado e envolvido em seu trabalho, sendo que o tempo passa rapidamente e o indivíduo possui dificuldade em desapegar-se de seu trabalho.

Para Schaufeli, Dijkstra e Vasquez (2013) o engajamento no trabalho possui características especificas, que podem ser consideradas como aspectos positivos possuindo três particularidades (dimensões):

- Vitalidade: Pessoas engajadas se sentem energizadas, fortalecidas e vibrantes no trabalho. Sentem autoconfiança e dificilmente se desencorajam nas atividades realizadas, mesmo nas adversidades.

- Dedicação: Pessoas engajadas se sentem conectadas ao trabalho e são entusiasmadas em suas tarefas. Elas realmente se importam com o que acontece no dia-adia do trabalho, assim como atribuem um significado positivo às suas atividades e sentem orgulho do que fazem.

- Concentração: Pessoas engajadas se sentem completamente imersas e absorvidas em suas atividades. Elas são focadas, consideram seu trabalho desafiador, sentem tanto prazer no trabalho que desenvolvem que, geralmente, se esquecem do tempo enquanto estão trabalhando.

Para avaliação do engajamento no trabalho Schaufeli e Bakker (2003) validaram o questionário denominado Utrech Work Engagement Scale (UWES), utilizado como instrumento de pesquisa para o assunto, através do qual, segundo os autores, é possível mensurar as dimensões do engajamento no trabalho, conforme ilustrado na tabela 1.

Tabela 1 - Itens de mensuração do nível de engajamento no trabalho segundo questionário Utrech Work Engagement Scale (UWES)

\begin{tabular}{|c|c|c|}
\hline Dimensão & Itens relacionados & Mensuração \\
\hline Vigor & $\begin{array}{l}\text { Em meu trabalho, sinto-me repleto (cheio) de energia; } \\
\text { No trabalho, sinto-me com força e vigor (vitalidade); } \\
\text { Quando me levanto pela manhã, tenho vontade de ir trabalhar; } \\
\text { Posso continuar trabalhando por longos períodos de tempo; } \\
\text { Em meu trabalho, sou uma pessoa mentalmente resiliente (versátil); } \\
\text { No trabalho, sou persistente mesmo quando as coisas não vão bem. }\end{array}$ & $\begin{array}{l}\text { Quanto mais alto a } \\
\text { pontuação identificada } \\
\text { nesta dimensão, mais } \\
\text { alto é o nível de energia } \\
\text { no trabalho. }\end{array}$ \\
\hline Dedicação & $\begin{array}{l}\text { Eu acho que o trabalho que realizo é cheio de significado e propósito; } \\
\text { Me sinto entusiasmado com o meu trabalho; } \\
\text { Meu trabalho me inspira; } \\
\text { Me sinto orgulhoso com o trabalho que realizo; } \\
\text { Sinto que meu trabalho é desafiador. }\end{array}$ & $\begin{array}{l}\text { Quanto maior o escore } \\
\text { neste item, mais a } \\
\text { pessoa se identifica com } \\
\text { o trabalho. }\end{array}$ \\
\hline Absorção & $\begin{array}{l}\text { O "tempo voa" quando estou trabalhando; } \\
\text { Quando estou trabalhando, esqueço tudo o que se passa ao meu } \\
\text { redor; } \\
\text { Sinto-me feliz quando trabalho intensamente; } \\
\text { Sinto-me envolvido com o trabalho que faço; } \\
\text { "deixo-me levar" pelo meu trabalho; } \\
\text { Tenho dificuldade em desligar-me do trabalho. }\end{array}$ & $\begin{array}{l}\text { Neste item, àqueles que } \\
\text { apresentam altos } \\
\text { escores sentem-se } \\
\text { envolvidos e imersos no } \\
\text { trabalho. }\end{array}$ \\
\hline
\end{tabular}

Fonte: Schaufeli e Bakker (2003) 
Para Schaufeli, Dijkstra e Vazquez (2013) pessoas engajadas no trabalho se dedicam não porque sentem alguma compulsão ou vicio interno para fazê-lo, mas porque sentem prazer tornando-se produtivas. Diferente de estar viciado no trabalho, onde a pessoa sente uma necessidade irresistível de trabalhar e dificilmente têm vida social fora do ambiente de trabalho.

Parodi (2015) complementa que o engajamento não depende só da empresa e da liderança. Características de personalidade como otimismo, automotivação, autoestima elevada, sentido de pertencer e influenciar colegas, ser alguém que está de bem com a vida e que se entusiasma com as buscas e conquistas também fazem muita diferença na construção de um time que tenha alto grau de engajamento.

\section{MÉTODO DE PESQUISA}

Visando responder ao objetivo deste estudo, empreendeu-se um estudo de cunho quantitativo, descritivo, do tipo survey, tendo por base uma amostra aleatória por conveniência com 132 profissionais que ocupam cargo de gestão e/ou são membros de equipes que possuam atividade formal de trabalho remunerado e atuem no estado do Rio Grande do Sul. Os dados foram coletados no período de dezembro/2016 à março de 2017.

Os questionários aplicados constituem-se de dois modelos teóricos: adaptação do Emotional Intelligence Appraisal ${ }^{\circledR}$, questionário elaborado por Travis Bradberry e Jean Greaves (2016) e, o UWES-17 (Utrecht Work Engagement Scale) - elaborado por Schaufeli e Bakker (2003) e adaptado por Angst, Benevides-Pereira e PortoMartins (2009), além de questões com a intenção de identificar o perfil dos respondentes (quadro 1).

Quadro 1- Modelos teóricos

\begin{tabular}{|l|l|}
\hline \multicolumn{1}{|c|}{ Modelos teóricos } & \multicolumn{1}{|c|}{ Descrição } \\
\hline $\begin{array}{l}\text { EIA - Emotional Intelligence Appraisal }{ }^{\circledR}, \\
\text { questionário elaborado por Travis } \\
\text { Bradberry e Jean Greaves (2016) e } \\
\text { adaptado para a pesquisa. }\end{array}$ & $\begin{array}{l}\text { Trata-se de um instrumento composto por 30 afirmativas, } \\
\text { estruturado e dividido em 5 fatores relacionadas entre si, mas } \\
\text { independentes: 6 para autoconsciência, 6 para autogestão, 6 } \\
\text { para automotivação, 6 para empatia e } 6 \text { para habilidade social. É } \\
\text { um questionário autoaplicável, do tipo Likert de } 7 \text { pontos que } \\
\text { variam de 0-6. }\end{array}$ \\
\hline $\begin{array}{l}\text { UWES-17 - Utrecht Work Engagement } \\
\text { Scale - elaborado por Schaufeli e Bakker } \\
\text { (2003) e adaptado por Angst, Benevides- } \\
\text { Pereira e PortoMartins (2009) }\end{array}$ & $\begin{array}{l}\text { Composto por 17 afirmativas, estruturado e divido em 3 fatores } \\
\text { relacionados entre si: vigor, dedicação e absorção, é um } \\
\text { questionário autoaplicável, do tipo Likert de 7 pontos que variam } \\
\text { de 0-6. }\end{array}$ \\
\hline
\end{tabular}

Fonte: Autores (2017)

A caracterização geral do perfil da amostra possui leve predominância de profissionais do gênero feminino (54,55\%), a maioria está na faixa entre 26 e 35 anos e residem no interior do estado do Rio Grande do Sul. Quanto ao nível de escolaridade, a maioria possui o ensino superior incompleto (49,24\%). 57,58\% dos respondentes não exerce cargo de gestão atualmente, porém destaca-se que, mesmo não sendo a maioria, há uma boa representação $(42,42 \%)$ de gestores na amostra. O setor de serviços $(45,45 \%)$ é a área de atuação a que pertence a maior parte da amostra (tabela 2 ). 
Tabela 2 - Caracterização geral do perfil da amostra

\begin{tabular}{|c|c|c|c|}
\hline Variáveis & Alternativas & Frequência & Percentual (\%) \\
\hline \multirow{2}{*}{ Gênero } & Feminino & 72 & $54,55 \%$ \\
\hline & Masculino & 60 & $45,45 \%$ \\
\hline \multirow{4}{*}{ Faixa Etária } & Menos de 25 anos & 36 & $27,27 \%$ \\
\hline & De 26 a 35 anos & 61 & $46,21 \%$ \\
\hline & De 36 a 45 anos & 20 & $15,15 \%$ \\
\hline & Mais de 46 anos & 15 & $11,36 \%$ \\
\hline \multirow{3}{*}{ Região onde reside } & Interior RS & 121 & $91,67 \%$ \\
\hline & Região Metropolitana RS & 10 & $7,58 \%$ \\
\hline & Outros & 1 & $0,76 \%$ \\
\hline \multirow{6}{*}{ Escolaridade } & Ensino fundamental & 0 & $0,00 \%$ \\
\hline & Ensino médio Incompleto & 1 & $0,75 \%$ \\
\hline & Ensino médio completo & 8 & $6,06 \%$ \\
\hline & Ensino superior incompleto & 65 & $49,24 \%$ \\
\hline & Ensino superior completo & 41 & $31,06 \%$ \\
\hline & Outros & 17 & $12,87 \%$ \\
\hline \multirow{2}{*}{ Ocupa cargo de gestão } & Sim & 56 & $42,42 \%$ \\
\hline & Não & 76 & $57,58 \%$ \\
\hline \multirow{5}{*}{ Área de atuação } & Indústria & 11 & $8,33 \%$ \\
\hline & Comércio & 42 & $31,82 \%$ \\
\hline & Serviços & 60 & $45,45 \%$ \\
\hline & Setor público & 10 & $7,58 \%$ \\
\hline & Outros & 9 & $6,81 \%$ \\
\hline
\end{tabular}

Fonte: Dados da pesquisa, 2017.

Após a tabulação dos dados, os mesmos passaram por análise estatística pelo software SPSS, versão 21. As análises estatísticas realizadas compreendem estatística descritiva, tabela de frequência e tabelas cruzadas. A fim de verificar a confiabilidade dos instrumentos, ou seja, o grau de consistência interna entre os indicadores de um fator aplicou-se o alpha de cronbach. Conforme Field (2009), valores entre 0,7 $\leq \alpha<0,8$ representam índices aceitáveis, $0,8 \leq \alpha<0,9$, representam um bom índice e $>0,9$, diz respeito a um ótimo índice de Alfa de Cronbach, sendo que valores $<0,6$ indicam escala não confiável. E por fim para, com o intuito de estabelecer a relação entre inteligência emocional e engajamento no trabalho, utilizou-se o cálculo do coeficiente de correlação de Pearson, o qual indica a força de associação entre as variáveis, e a classificação proposta por Lopes (2016) quanto a interpretação da fiabilidade do coeficiente de correlação de Pearson.

\section{RESULTADOS E DISCUSÕES}

\section{Análise da incidência de níveis de inteligência emocional}

Para, mensurar e analisar a incidência de níveis de inteligência emocional na amostra pesquisada, foi utilizado uma adaptação ao instrumento Emotional Intelligence Appraisal ${ }^{\circledR}$, questionário elaborado por Travis Bradberry e Jean Greaves (Bradberry e Greaves, 2016). Ele é um questionário autoaplicável, do tipo Likert de 7 pontos que variam de $0=$ "nunca", 1= "raramente", 2= "às vezes", 3= "frequentemente, 4= "quase sempre", 5= "sempre", 6= "todos os dias". Composto por 30 afirmativas sendo seis para autoconsciência, seis para autogestão, seis para automotivação, seis para empatia e seis para habilidade social. 
Segundo Goleman (1995) o conceito de inteligência emocional pauta-se em cinco habilidades básicas e interdependentes denominadas por autoconsciência, autogestão, automotivação, empatia e habilidade social. As três primeiras referem-se a exames de reações do do indivíduo e, ao que ele faz com seus próprios sentimentos, enquanto que as duas últimas se voltam para fora, em direção aos sentimentos dos outros e às interações sociais.

Na tabela 3 é apresentada a estatística descritiva da amostra, apresentando a média e desvio padrão da primeira habilidade de inteligência emocional, a autoconsciência.

O desvio padrão, segundo Mendenhall (1985) é a medida mais comum da dispersão estatística, ele mostra o quanto de dispersão ou variação existe em relação à média. Um baixo desvio padrão indica que os dados tendem a estar próximos da média, enquanto for alto os dados estão espalhados por uma gama de valores.

Para Raiol (2008) a autoconsciência é a base sobre a qual são construídas todas as aptidões da inteligência emocional e a partir da qual é possível monitorar-se, fazendo com que os próprios atos funcionem em seu benefício.

Tabela 3 - Estatística descritiva da dimensão autoconsciência.

\begin{tabular}{l|l|l|l}
\hline Número & Questão (autoconsciência) & Média & Desvio padrão \\
\hline $\mathbf{1}$ & Tem total consciência de suas capacidades & 4,60 & 1,09 \\
\hline $\mathbf{2}$ & Admite e reconhece seus defeitos e fraquezas & 4,48 & 1,20 \\
\hline $\mathbf{3}$ & $\begin{array}{l}\text { Conseguem entender as emoções no } \\
\text { momento em que ocorrem }\end{array}$ & $\mathbf{4 , 1 9}$ & $\mathbf{1 , 2 0}$ \\
\hline $\mathbf{4}$ & $\begin{array}{l}\text { Reconhece o impacto do seu comportamento } \\
\text { nos outros }\end{array}$ & $\mathbf{4 , 5 6}$ & $\mathbf{1 , 1 2}$ \\
\hline $\mathbf{5}$ & $\begin{array}{l}\text { Percebe que os outros influenciam seu estado } \\
\text { emocional }\end{array}$ & $\mathbf{4 , 8 0}$ & $\mathbf{1 , 2 4}$ \\
\hline $\mathbf{6}$ & $\begin{array}{l}\text { Sente-se responsável pela situação emocional } \\
\text { em que se encontra atualmente }\end{array}$ & 5,05 & $\mathbf{0 , 9 5}$ \\
\hline Média Geral: & & $\mathbf{4 , 5 0}$ & $\mathbf{1 , 2 2}$ \\
\hline
\end{tabular}

Fonte: Dados da pesquisa, 2017

Desta forma, como demonstrado na tabela 3, a questão "sente-se responsável pela situação emocional em que se encontra atualmente" (6), foi a que obteve a maior média desta habilidade com 5,05 e um DP=0,95. A questão "Conseguem entender as emoções no momento em que ocorrem" (3), foi a que apresentou a menor média 4,19 e $D P=1,20$. A dimensão de autoconsciência apresentou uma média geral de 4,50 e um DP=1,22.

Segundo Mersino (2009), primeiro ponto para a inteligência emocional é autoconsciência, a capacidade do ser humano de entender emoções. Caso ela não esteja bem solidificada, existe uma grande possibilidade dos outros aspectos da inteligência emocional não funcionarem. Por ser difícil identificar quais sentimentos são vivenciados, o corpo pode transparecer as emoções em sensações físicas como expressões faciais, dores, tensões físicas e alertas emocionais como humor inadequado, sarcasmo, comportamento passivo-agressivo, hostilidade, etc.

Na tabela 4 é apresentada a estatística descritiva da amostra, apresentando a média e desvio padrão da segunda habilidade de inteligência emocional, autogestão.

A autogestão é a capacidade de usar a conscientização das emoções para manter flexíveis e direcionar o comportamento de forma positiva. Isso implica gerenciar as reações emocionais a diferentes situações e pessoas (BRADBERRY; GREAVES, 2016, P.31). 
Conforme apresenta a tabela 4, a questão "esforça-se para aproveitar ao máximo as situações (boas ou ruins) (12), foi a que apresentou a maior média 4,73 e DP=1,01. A questão de número 10 "tolera frustrações com certa facilidade" obteve a menor média com 3,51 e um $D P=1,34$, sendo que foi a que a presentou a menor média entre as questões desta habilidade de inteligência emocional. A média geral na dimensão "autogestão" foi de 4,28 e um $\mathrm{DP}=1,28$.

Tabela 4 - Estatística descritiva da dimensão autogestão.

\begin{tabular}{l|l|l|l}
\hline Número & Questão (autogestão) & Média & Desvio padrão \\
\hline $\mathbf{7}$ & Lida bem com pressões profissionais & 4,35 & 1,24 \\
\hline $\mathbf{8}$ & $\begin{array}{l}\text { Lida bem com momentos de estresse do dia- } \\
\text { a-dia }\end{array}$ & $\mathbf{4 , 1 0}$ & 1,22 \\
\hline $\mathbf{9}$ & $\begin{array}{l}\text { Conseguem identificar a origem dos seus } \\
\text { sentimentos (bons ou ruins) }\end{array}$ & $\mathbf{4 , 3 0}$ & 1,21 \\
\hline $\mathbf{1 0}$ & Tolera frustrações com certa facilidade & 3,51 & 1,34 \\
\hline $\mathbf{1 1}$ & $\begin{array}{l}\text { Considera muitas opções antes de tomar uma } \\
\text { decisão }\end{array}$ & $\mathbf{4 , 6 4}$ & $\mathbf{1 , 2 8}$ \\
\hline $\mathbf{1 2}$ & $\begin{array}{l}\text { Esforça-se para aproveitar ao máximo as } \\
\text { situações (boas ou ruins) }\end{array}$ & $\mathbf{4 , 7 3}$ & $\mathbf{1 , 0 1}$ \\
\hline Média Geral: & & $\mathbf{4 , 2 8}$ & $\mathbf{1 , 2 8}$ \\
\hline
\end{tabular}

Fonte: Dados da pesquisa, 2017

Decorrente da autoconsciência, a autogestão agrega competências como autocontrole, transparência, adaptabilidade, superação, iniciativa e otimismo. Nenhum líder pode encarar emoções negativas, como raiva, pânico, ansiedade ou frustração, porque as emoções são contagiantes, especialmente as provenientes dos líderes. Esses não poderão ser eficazes no gerenciamento de pessoas se não adquirirem a habilidade de lidar com as próprias emoções (GOLEMAN, 1999).

Para Bradberry e Greaves (2016) as pessoas com uma boa capacidade de autogestão conseguem avaliar com clareza a situação sem ceder às tentações. As pessoas capazes de postergar a satisfação de suas necessidades imediatas e gerenciar continuamente as próprias tendências têm mais chances de conquistar o sucesso.

A tabela 5 apresenta a estatística descritiva da amostra, apresentando a média e desvio padrão da terceira habilidade de inteligência emocional, "automotivação". Para Branco (2004) a automotivação manifesta-se quando, o indivíduo acha que, faz sentido para enfrentar qualquer situação independentemente da dificuldade que esta apresente.

Tabela 5 - Estatística descritiva da dimensão automotivação.

\begin{tabular}{l|l|l|l}
\hline Número & Questão (automotivação) & Média & Desvio padrão \\
\hline $\mathbf{1 3}$ & $\begin{array}{l}\text { Tem facilidade em pensar positivo mesmo em } \\
\text { situação adversa }\end{array}$ & 4,26 & 1,34 \\
\hline $\mathbf{1 4}$ & Tem consciência do que o motiva & 4,68 & 1,23 \\
\hline $\mathbf{1 5}$ & Possui objetivos claros e foco no seu atingimento & 4,48 & 1,21 \\
\hline $\mathbf{1 6}$ & $\begin{array}{l}\text { Tem facilidade de recuperar-se de situações adversas } \\
\text { (resiliência) }\end{array}$ & $\mathbf{4 , 3 4}$ & 1,25 \\
\hline $\mathbf{1 7}$ & $\begin{array}{l}\text { Busca identificar rapidamente a origem dos } \\
\text { sentimentos negativos }\end{array}$ & $\mathbf{4 , 3 2}$ & $\mathbf{1 , 2 3}$ \\
\hline $\mathbf{1 8}$ & $\begin{array}{l}\text { Trabalha para reverter situações de incomodo e } \\
\text { estresse }\end{array}$ & $\mathbf{4 , 5 9}$ & $\mathbf{1 , 2 2}$ \\
\hline Média Geral: & & $\mathbf{4 , 4 5}$ & $\mathbf{1 , 2 5}$ \\
\hline
\end{tabular}

Fonte: Dados da pesquisa, 2017

RGO REVISTA GESTÃO ORGANIZACIONAL | VOL 11 - № 1 - JAN./ABR. - 2018 
A partir do exposto na tabela 5, pode se verificar que a questão com maior média entre as dimensões de automotivação é a de número 14 "Tem consciência do que o motiva", com média de 4,68 e um $\mathrm{DP}=1,23$. A questão de número 17 "busca identificar rapidamente a origem dos sentimentos negativos foi a que obteve a menor média desta habilidade, com 4,32 e um $D P=1,23$. A média geral na dimensão automotivação foi de 4,45 e um DP=1m25.

Para Branco (2004) a automotivação ou motivar a si mesmos, significa a capacidade de utilizar a energia das emoções em função de objetivos próprios, e acreditar (ter a esperança) que serão cumpridos, utilizando essa energia para fabricar a atenção, melhorar o nível de concentração e poder entrar em estado de fluxo.

A tabela 6 apresenta a estatística descritiva da amostra, apresentando a média e desvio padrão da quarta habilidade de inteligência emocional - empatia.

Um dos conceitos mais simples no que diz respeito a definição da empatia é atribuído a Krznaric (2015), que a define como "a arte de se colocar no lugar do outro por meio da imaginação, compreendendo seus sentimentos e perspectivas, usando essa compreensão para guiar as próprias ações". Segundo Rogers e Kinget (1977) a compreensão empática é um processo dinâmico que significa, capacidade de penetrar no universo perceptivo do outro, sem julgamentos, tomando consciência dos seus sentimentos, sem, no entanto, deixar de respeitar o seu ritmo de descoberta de si próprio.

Tabela 6 - Estatística descritiva da dimensão empatia.

\begin{tabular}{l|l|l|l}
\hline Número & Questão (empatia) & Média & Desvio padrão \\
\hline $\mathbf{1 9}$ & Sente-se aberto a feedback & 4,92 & 1,15 \\
\hline $\mathbf{2 0}$ & Percebe os sentimentos dos outros & 4,44 & 1,16 \\
\hline $\mathbf{2 2}$ & $\begin{array}{l}\text { Tem facilidade de entender o ponto de vista } \\
\text { do outro, mesmo quando ele o critica }\end{array}$ & $\mathbf{4 , 2 2}$ & 1,17 \\
\hline $\mathbf{2 3}$ & $\begin{array}{l}\text { Demonstra aos outros que você se importa } \\
\text { com o que eles estão sentindo }\end{array}$ & $\mathbf{4 , 5 6}$ & $\mathbf{1 , 1 8}$ \\
\hline $\mathbf{2 4}$ & $\begin{array}{l}\text { Usa a sensibilidade em relação ao sentimento } \\
\text { do outro para moldar suas atitudes }\end{array}$ & $\mathbf{4 , 3 8}$ & $\mathbf{1 , 1 8}$ \\
\hline Média Geral: & $\begin{array}{l}\text { Procura explicar seu ponto de vista, } \\
\text { ponderando o ponto de vista do outro }\end{array}$ & $\mathbf{4 , 5 9}$ & $\mathbf{1 , 0 8}$ \\
\hline
\end{tabular}

Fonte: Dados da pesquisa, 2017

Conforme apresenta a tabela 6, a questão 19 "Sente-se aberto a feedback" é a que apresenta a maior média com 4,92 e um DP=1,15. Por outro lado, a questão "Tem facilidade de entender o ponto de visto do outro, mesmo quando ele o critica", (21), foi a que apresentou a menor média entre as questões desta habilidade, com 4,22 e um DP=1,17. A média geral na dimensão "empatia" foi de 4,52 e um DP=1,17.

Na tabela 7 é apresentada a estatística descritiva da amostra, apresentando a média e desvio padrão da quinta e última habilidade de inteligência emocional, "habilidade social".

A questão 28 "Sente-se bem em fazer parte de um grupo/equipe" foi a que apresentou a maior média entre os pesquisados com 5,19 e um $\mathrm{DP}=0,99$, já a questão 29 "Busca envolver os outros em suas atividades" foi a que apresentou a menor média desta dimensão, com 4,56 e um DP=1,25. A média da dimensão "habilidade social" foi de 4,91 e um DP=1,08 (tabela 7). 
Tabela 7 - Estatística descritiva da dimensão habilidade social.

\begin{tabular}{|c|c|c|c|}
\hline Número & Questão (habilidade social) & Média & Desvio padrão \\
\hline 25 & $\begin{array}{l}\text { Tem bons relacionamentos nos ambientes em } \\
\text { que convive }\end{array}$ & 5,18 & 0,83 \\
\hline 26 & Comunica-se de maneira clara e eficaz & 4,83 & 1,02 \\
\hline 27 & $\begin{array}{l}\text { Tem facilidade em perceber o clima do } \\
\text { ambiente }\end{array}$ & 4,98 & 0,92 \\
\hline 28 & $\begin{array}{l}\text { Sente-se bem em fazer parte de um } \\
\text { grupo/equipe }\end{array}$ & 5,19 & 0,99 \\
\hline 29 & Busca envolver os outros em suas atividades & 4,56 & 1,25 \\
\hline 30 & $\begin{array}{l}\text { Tem facilidade em trabalhar em ambientes } \\
\text { com várias pessoas }\end{array}$ & 4,72 & 1,28 \\
\hline \multicolumn{2}{|c|}{ Média Geral: } & 4,91 & 1,08 \\
\hline
\end{tabular}

Fonte: Dados da pesquisa, 2017

A habilidade social é a culminância das outras dimensões da inteligência emocional. As pessoas tendem a ser bem eficazes em gerir relacionamentos quando conseguem entender e controlar suas próprias emoções e conseguem ser empáticos com os sentimentos dos outros (GOLEMAN, 2015, P.23).

Na tabela 8 são apresentadas as estatísticas descritivas dos resultados da amostra, apresentando média e desvio padrão das cinco habilidades da inteligência emocional.

Tabela 8 - Estatística descritiva das cinco habilidades da inteligência emocional.

\begin{tabular}{l|l|l|l}
\hline Questões & Habilidade & Média & Desvio padrão \\
\hline $1,2,3,4,5,6$ & Autoconsciência & 4,50 & 1,22 \\
\hline $7,8,9,10,11,12$ & Auto-Gestão & 4,28 & 1,28 \\
\hline $13,14,15,16,17,18$ & Automotivação & 4,45 & 1,25 \\
\hline $19,20,21,22,23,24$ & Empatia & 4,52 & 1,17 \\
\hline $25,26,27,28,29,30$ & Habilidade Social & 4,91 & 1,08 \\
\hline Média Geral: & & $\mathbf{4 , 5 6}$ & $\mathbf{1 , 2 1}$ \\
\hline
\end{tabular}

Fonte: Dados da pesquisa, 2017

A dimensão de inteligência emocional com maior média foi "habilidade social", com 4,91 e um desvio padrão de 1,08. Já a dimensão autogestão foi a que registrou a menor média com 4,28 e um desvio padrão de 1,28, no entanto todas dimensões de inteligência emocional apresentaram pouca variação em relação tanto a média (de 4,28 a 4,91) quanto ao desvio padrão (de 1,08 a 1,28), o que pode representar que a amostra é homogênea (tabela 8).

Com referência as cinco habilidades da inteligência emocional, a autoconsciência significa uma compreensão das próprias emoções, forças, fraquezas, necessidades e impulsos. Automotivação é a capacidade de se manter motivado, resiliente. Autogestão é o que é chamado de autocontrole, uma conversa interior contínua com o objetivo de libertar de ser prisioneiros dos próprios sentimentos. Empatia, que de todas as dimensões da inteligência emocional é a mais fácil de ser percebida, significa levar em conta ponderadamente os sentimentos dos outros. Habilidade Social que é a capacidade de uma pessoa se relacionar com outras (GOLEMAN, 1999).

A partir dos resultados obtidos, considera-se que a amostra pesquisada possui o sentimento de inteligência emocional médio e alto, considerando suas cinco dimensões. Para se calcular a média de uma escala Likert, conforme Lopes (2016), é preciso esclarecer o nível atingido por cada conjunto de variáveis, a padronização destes escores permite a 
qualificação da soma dos resultados em medidas classificatórias, podendo ser transformado em três categorias, que são elas: baixa, média ou intermediária e alta. Seguindo este conceito, para mensuração dos níveis de inteligência emocional são definidos como baixo, médio e alto.

Ainda, a padronização dos escores para Lopes (2016) é obtida por meio da seguinte operação matemática: soma-se os valores validos subtraídos da menor soma possível, o resultado e dividido pela maior soma possível subtraído da menor soma possível, multiplicado por 10 ou 100 (valor em percentual). O cálculo Escore Padronizado (Epi) e representado através da seguinte formula:

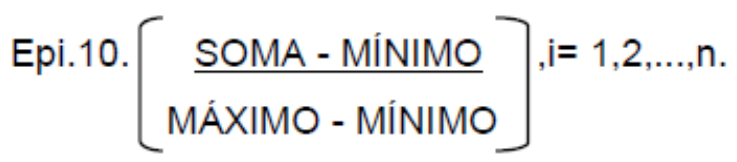

No gráfico 2 são apresentados os índices gerais dos níveis de inteligência emocional, classificados em alta, média e baixa na amostra pesquisada.

Gráfico 2 - Nível geral de incidência das dimensões de inteligência emocional na amostra

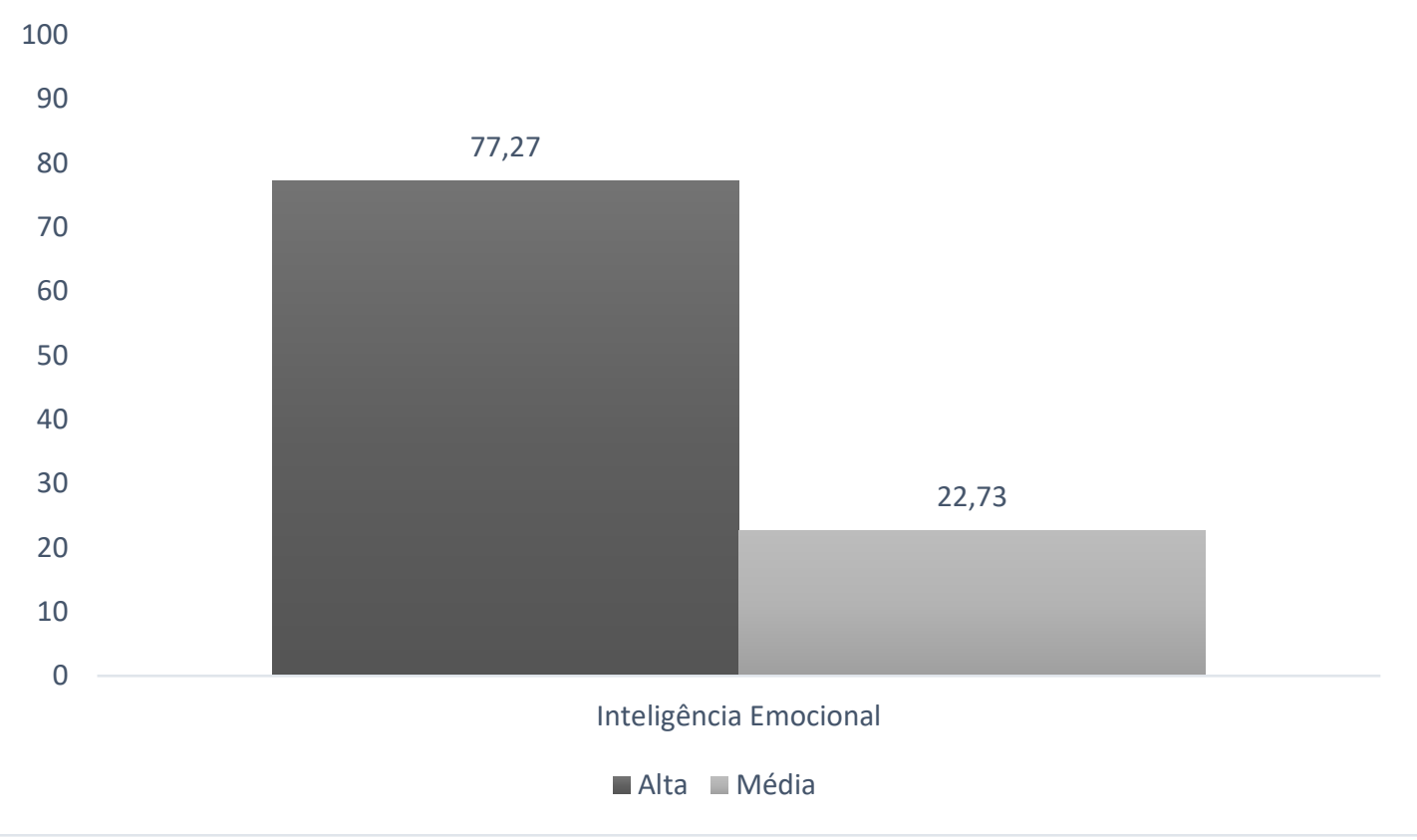

Fonte: Dados da pesquisa, 2017

Conforme exposto no gráfico $2,77,27 \%$ da amostra estão com altos níveis gerais de inteligência emocional e 22,73\% apresentam médios índices de inteligência emocional no ambiente de trabalho, deste modo pode-se considerar que a maioria dos respondentes em questão apresenta altos índices de inteligência emocional.

Com a finalidade de verificar a confiabilidade ou o grau de consistência interna entre os indicadores de um fator, aplicou-se o Alpha de Cronbach. Field (2009) considera que valores entre 0,7 $\leq a<0,8$ representam índices aceitáveis, entre $0,8 \leq a<0,9$, diz respeito a um bom índice, $>0,9$ diz respeito a um ótimo índice e valores $<0,6$ indicam escala não confiável de Alpha de Cronbach.

$\mathrm{Na}$ tabela 9 são apresentados os resultados relativos ao alpha de Cronbach das dimensões de inteligência emocional. 
Tabela 9 - Alpha de Cronbach das dimensões da inteligência emocional

\begin{tabular}{l|l|l}
\hline Fator & Variáveis & Alpha de Cronbach \\
\hline Autoconsciência & $1,2,3,4,5,6$ & 0,468 \\
\hline Autogestão & $7,8,9,10,11,12$ & 0,779 \\
\hline Automotivação & $13,14,15,16,17,18$ & 0,826 \\
\hline Empatia & $19,20,21,22,23,24$ & 0,778 \\
\hline Habilidade Social & $25,26,27,28,29,30$ & 0,831 \\
\hline & $\mathbf{0 , 9 1 8}$
\end{tabular}

Fonte: Dados da pesquisa, 2017.

A partir do alpha de Cronbach, tendo em vista os índices encontrados, é possível perceber que das cinco dimensões da inteligência emocional, a autoconsciência apresenta uma escala não aceitável ( $\alpha$ de 0,46 ), a autogestão e a empatia apresentam associação aceitável ( $\alpha$ de 0,77$)$ e a automotivação $(\alpha$ de 0,82 ) e a habilidade social $(\alpha$ de 0,83 ) apresentam boa associação entre as variáveis. Ao analisar o instrumento como um todo, obteve-se alpha de Cronbach de 0,918 que pode ser considerado um ótimo índice de confiabilidade do instrumento para a amostra do presente estudo.

Cabe ressaltar que mesmo com os resultados encontrados, onde a maioria em questão apresenta altos níveis de inteligência emocional, a avaliação foi realizada a partir de um auto relato, ou seja, a partir do sentimento de ter ou não a habilidade pesquisada. Neste sentido Brackett e Mayer (2003), apontam que a pesquisa em inteligência emocional se expandiu nos últimos anos e atualmente conta com diversos instrumentos de avaliação. Contudo, o campo da inteligência emocional tem se caracterizado por dificuldades de mensuração, devido aos problemas teóricos de delimitação de construto e devido aos tipos de instrumentos utilizados para medir essa aptidão. Em linhas gerais a inteligência emocional pode ser medida através de instrumentos de avaliação de dois tipos: os de desempenho, que medem a performance de determinado sujeito em tarefas específicas e os de auto relatos, que constituem questionários onde o sujeito reporta as habilidades que acredita possuir.

Contudo, apesar dos problemas referentes às psicométricas das escalas de auto relato, alguns autores defendem sua validade no âmbito da pesquisa, na medida em que possibilitariam a investigação da autopercepção (ROBERTS; FLORES-MENDOZA; NASCIMENTO, 2002).

\section{Análise da incidência de níveis de dimensões de Engajamento no Trabalho: vigor, dedicação e absorção}

Hallberg e Schaufeli (2006) ilustram o engajamento com as atividades de trabalho como um estado de completa energia e dedicação à realização de uma função, estando dividido em três dimensões: vigor, dedicação e absorção.

Neste sentido, para responder o terceiro objetivo específico, mensurar e analisar a incidência de níveis de dimensões de engajamento no trabalho da amostra pesquisada, foi utilizado o instrumento UWES (Utrecht Work Engagement Scale), elaborado por Wilmar B.Shaufeli e Arnold Bakker em 2003, composto por 17 afirmativas, sendo 6 para vigor (questões: 1,4,8,12,15 e 17), 5 para dedicação (questões: 2,5,7,10 e 13), e 6 para absorção (questões: 3,6,9,11,14 e 16). É um questionário autoaplicável, do tipo Likert de 7 pontos que variam de $0=$ "nunca", 1= "uma vez ao ano ou menos", 2= "uma vez ao mês ou menos", 3= "algumas vezes ao mês", 4= "uma vez por semana", 5= "algumas vezes por semana", 6= "todos os dias". O instrumento tem a sua validade confirmada através de resultados 
psicométricos, consistindo em três escalas que são altamente relacionadas (SCHAUFELI E BAKKER 2003).

Na tabela 10 é apresentada a estatística descritiva da amostra, apresentando a média e desvio padrão da primeira dimensão do engajamento, "vigor". Segundo Shaufeli e Bakker (2003) o vigor caracteriza-se pelos altos níveis de energia e resiliência mental enquanto trabalha, vontade de investir no trabalho, e persistência em situações de dificuldade.

Tabela 10 - Estatística descritiva da dimensão "vigor".

\begin{tabular}{|c|c|c|c|}
\hline Número & Questão (Vigor) & Média & Desvio padrão \\
\hline 1 & Em meu trabalho, sinto-me repleto (cheio) de energia & 4,40 & 1,17 \\
\hline 4 & No trabalho, sinto-me com força e vigor (vitalidade) & 4,77 & 1,23 \\
\hline 8 & $\begin{array}{l}\text { Quando me levanto pela manhã, tenho vontade de ir } \\
\text { trabalhar. }\end{array}$ & 4,62 & 1,18 \\
\hline 12 & $\begin{array}{l}\text { Posso continuar trabalhando durante longos períodos de } \\
\text { tempo }\end{array}$ & 4,41 & 1,12 \\
\hline 15 & $\begin{array}{l}\text { Em meu trabalho, sou uma pessoa mentalmente resiliente } \\
\text { (versátil). }\end{array}$ & 4,43 & 1,27 \\
\hline 17 & $\begin{array}{l}\text { No trabalho, sou persistente mesmo quando as coisas não } \\
\text { vão bem }\end{array}$ & 3,90 & 1,27 \\
\hline \multicolumn{2}{|c|}{ Média Geral: } & 4,43 & 1,23 \\
\hline
\end{tabular}

Fonte: Dados da pesquisa, 2017

Como demonstrado na tabela 10, a questão "no trabalho, sinto-me com força e vigor (vitalidade) " (4), obteve a maior média 4,77 DP =1,23. Por outro lado, a questão "no trabalho, sou persistente mesmo quando as coisas não vão bem" (17), foi a que obteve uma média menor, 3,90 DP=1,27. A dimensão vigor apresentou uma média geral de 4,43 e um desvio padrão de 1,23. Conforme Shaufeli e Bakker (2003) quanto mais alto o escore identificado em vigor, mais alto o nível de energia no trabalho.

Na tabela 11 é apresentada a estatística descritiva da amostra, apresentando a média e desvio padrão da segunda dimensão do engajamento, "dedicação".

Tabela 11 - Estatística descritiva da dimensão "dedicação".

\begin{tabular}{l|l|l|l}
\hline Número & Questão (Dedicação) & Média & Desvio padrão \\
\hline 2 & $\begin{array}{l}\text { Eu acho que o trabalho que realizo é cheio de } \\
\text { significado e propósito }\end{array}$ & 4,30 & 1,30 \\
\hline 5 & Estou entusiasmado com meu trabalho & 4,31 & 1,37 \\
\hline 7 & Meu trabalho me inspira & 4,75 & 1,25 \\
\hline 10 & Estou orgulhoso com o trabalho que realizo & 4,87 & 1,24 \\
\hline 13 & Para mim meu trabalho é desafiador & 4,88 & 1,22 \\
\hline Média Geral: & & $\mathbf{4 , 6 3}$ & $\mathbf{1 , 3 0}$ \\
\hline
\end{tabular}

Fonte: Dados da pesquisa, 2017

A questão "para mim meu trabalho é desafiador" (13), obteve a maior média com 4,88 e $\mathrm{DP}=1,22$. Já a questão 2 "eu acho que o trabalho que realizo é cheio de significado e proposito" obteve a menor média 4,30 e um $D P=1,30$. Destaca-se também a proximidade entre as médias apresentadas nas 5 questões desta dimensão (tabela 11). Ao apresentar altos escores de dedicação é porque a pessoa se identifica com o seu trabalho, percebe como algo de significado, inspirador e desafiador sentindo entusiasmo e orgulho em relação ao trabalho (SHAUFELI; BAKKER, 2003). 
Na tabela 12 é apresentada a estatística descritiva da amostra, apresentando a média e desvio padrão da terceira dimensão do engajamento, "absorção".

Tabela 12 - Estatística descritiva da dimensão "absorção"

\begin{tabular}{l|l|l|l}
\hline Número & Questão (Absorção) & Média & Desvio padrão \\
\hline 3 & O “tempo voa" quando estou trabalhando & 4,51 & 1,32 \\
\hline 6 & $\begin{array}{l}\text { Quando estou trabalhando, esqueço tudo o } \\
\text { que se passa ao meu redor }\end{array}$ & 4,73 & 1,31 \\
\hline 9 & Sinto-me feliz quando trabalho intensamente & 4,07 & 1,32 \\
\hline 11 & Sinto-me envolvido com o trabalho que faço & 4,84 & 0,99 \\
\hline 14 & "Deixo-me levar" pelo meu trabalho & 3,73 & 1,46 \\
\hline 16 & É difícil desligar-me do trabalho & 4,70 & 1,13 \\
\hline Média Geral: & & $\mathbf{4 , 4 4}$ & $\mathbf{1 , 3 2}$ \\
\hline
\end{tabular}

Fonte: Dados da pesquisa, 2017

A afirmativa "Sinto-me envolvido com o trabalho que faço" (11), foi a que obteve a maior média com 4,84 DP=0,99. A questão 14 cujo a afirmação é "Deixo-me levar pelo meu trabalho" foi a que obteve a menor média com 3,73 DP=1,46. Pessoas engajadas se sentem completamente imersas e absorvidas em suas atividades. Elas são focadas, consideram seu trabalho desafiador, sentem tanto prazer no trabalho que desenvolvem que, geralmente, se esquecem do tempo enquanto estão trabalhando (SCHAUFELI; DIJKSTRA; VASQUEZ, 2013).

Schaufeli e Bakker (2003) afirmam que, quanto mais alto o escore identificado em vigor, dedicação e absorção, maior será o engajamento no trabalho. Com isso, e a partir dos resultados obtidos, pode considerar-se que, a amostra em questão apresenta alto nível de engajamento no trabalho, pois, a dimensão "vigor" apresentou uma média de 4,33, a segunda dimensão "dedicação", obteve média de 4,63, e a terceira dimensão absorção apresentou a média de 4,44 na amostra pesquisada.

No gráfico 4, são apresentados os índices gerais dos níveis de engajamento no trabalho, classificados em alta, média e baixa na amostra pesquisada.

Gráfico 4 - Nível geral de incidência das dimensões de engajamento na amostra 100

80

67,33

60

40

20

0

30,33

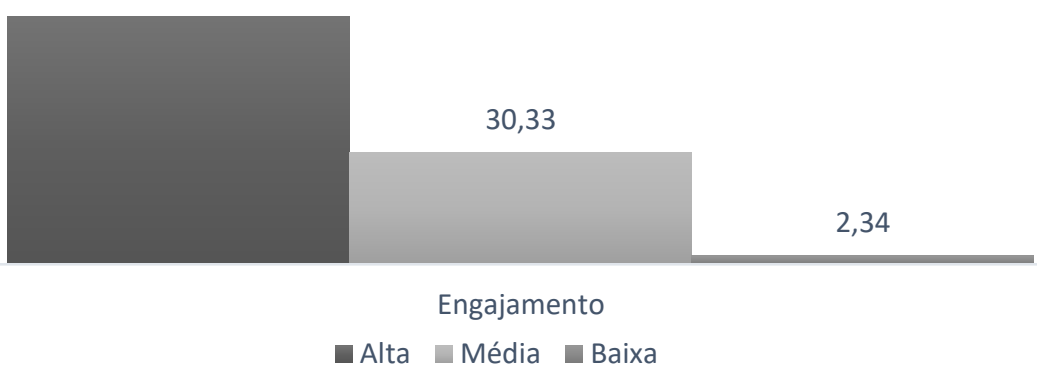

Fonte: Dados da pesquisa, 2017

Conforme exposto no gráfico 4, 67,33\% da amostra estão com altos níveis de engajamento no ambiente de trabalho, 30,33\% apresentam médios índices de engajamento e, apenas 2,34\% podem ser considerados não engajados. De acordo com Schaufeli e Bakker (2003) quanto mais alto o escore identificado em vigor, dedicação e absorção, maior será o engajamento no trabalho, sendo assim considera-se que a amostra em questão está engajada, pois apresenta altos índices de engajamento. 
Para comprovar a fidedignidade do método utilizado, dois aspectos de confiabilidade são considerados: a consistência interna e a confiabilidade teste-reteste, também denominado estabilidade, através da média baseada nas amostras de 9 países, indicando os Coeficientes Alfas de Crombach aceitáveis (Vigor $=\alpha$ de 0,82; Dedicação $=\alpha$ de 0,89; e Absorção $=\alpha$ de 0,83 com escore total de 0,93). Apesar de diferenças nos níveis de engajamento terem sido computadas entre países, estas são difíceis de interpretar, na medida em que a composição das amostras de diversos países se diferenciam em uma grande extensão (SCHAUFELI; BAKKER, 2003).

Na tabela 13 são apresentados os resultados relativos ao alpha de Cronbach das dimensões de engajamento no trabalho.

Tabela 13 - Alpha de Cronbach das dimensões do engajamento

\begin{tabular}{l|l|l}
\hline Fator & Variáveis & Alpha de Cronbach \\
\hline Vigor & $1,4,8,12,15$ e 17 & 0,925 \\
\hline Dedicação & $2,5,7,10$ e 13 & 0,917 \\
\hline Absorção & $3,6,9,11,14$ e 16 & 0,799 \\
\hline
\end{tabular}

Fonte: Dados da pesquisa, 2017.

A partir do alpha de Cronbach, tendo em vista os índices encontrados, é possível perceber que as três dimensões apresentam boa associação entre as variáveis, sendo que apenas a dimensão absorção ficou um pouco abaixo. Porém, ao analisar o instrumento como um todo, obteve-se alpha de Cronbach de 0,952 que está muito próximo do escore das amostras de 9 países, sendo considerado ótimo índice de confiabilidade do instrumento para a amostra do presente estudo.

Por fim, para responder ao objetivo deste estudo, buscando identificar possíveis relações entre a inteligência emocional e as dimensões do engajamento no trabalho de gestores e membros de equipes, utilizou-se o cálculo do coeficiente de correlação de Pearson, o qual indica a força de associação entre as variáveis.

Para Lopes (2016), em estatística descritiva, coeficiente de correlação de Pearson tem como objetivo encontrar e mensurar o grau de relação entre duas variáveis, ou seja, um coeficiente de correlação, envolvendo dados contínuos conhecidos como " $r$ de Pearson". Podendo assumir valores positivos (+) ou negativos (-). A magnitude de " $r$ " indica quão próximos da "reta" estão os pontos individuais. Sendo que, quando o $r$ se aproxima de 1 significa uma correlação perfeita positiva entre as duas variáveis.

Na tabela 14 são apresentados a classificação para o coeficiente.

Tabela 14 - Classificação do coeficiente de correlação de Pearson

\begin{tabular}{l|l}
\hline Valor de $r$ (+ ou -$)$ & Interpretação \\
\hline 0,00 & Nula \\
\hline 0,01 a 0,20 & Íntima fraca \\
\hline 0,21 a 0,40 & Fraca \\
\hline 0,41 a 0,60 & Moderada \\
\hline 0,61 a 0,80 & Forte \\
\hline 0,81 a 0,99 & Íntima forte \\
\hline 1,00 & Perfeita \\
\hline
\end{tabular}

Fonte: Lopes (2016) 
Neste sentido, busca-se avaliar a relação entre as habilidades de inteligência emocional e as dimensões de engajamento no ambiente de trabalho, nesta amostra todos os fatores estão positivamente correlacionados conforme se espera. Na tabela 15 são relacionadas as correlações de Pearson da amostra pesquisada.

Tabela 15 - Correlação de Pearson entre as dimensões de inteligência emocional e as dimensões de engajamento na amostra.

\begin{tabular}{lllll}
\hline & Vigor & Dedicação & Absorção & Engajamento \\
\hline Autoconhecimento & 0,29505 & 0,31210 & 0,33262 & 0,33348 \\
\hline Autogestão & 0,35663 & 0,42125 & 0,36579 & 0,40626 \\
\hline Automotivação & 0,58821 & $\mathbf{0 , 6 1 1 9 8}$ & 0,53880 & $\mathbf{0 , 6 1 9 1 8}$ \\
\hline Empatia & 0,49898 & 0,50442 & 0,45253 & 0,51857 \\
\hline Habilidade Social & 0,53288 & 0,56968 & 0,45203 & 0,55409 \\
\hline Inteligência Emocional & 0,57352 & $\mathbf{0 , 6 1 1 3 4}$ & 0,53783 & $\mathbf{0 , 6 1 3 0 9}$ \\
\hline
\end{tabular}

Fonte: Lopes (2016)

Os fatores que apresentam forte correlação positiva estão entre automotivação e dedicação $(0,61198)$. Ou seja, quanto maior for o nível de automotivação, maior será a sua dedicação. Do mesmo modo, correlacionando a dimensão automotivação com o constructo engajamento $(0,61918)$ e a dimensão dedicação com o constructo inteligência emocional $(0,61134)$. Em resposta ao objetivo, pode-se afirmar que, existe relação entre a Inteligência Emocional e o Engajamento no Trabalho $(0,61309)$ e esta relação é forte e positiva, ou seja, quanto maior o índice de inteligência emocional que o profissional apresentar, maior será o seu engajamento em relação ao seu trabalho.

\section{CONCLUSÃO E CONSIDERAÇÕES FINAIS}

Ao findar este estudo, observou-se primeiramente que a amostra pesquisada, possui como característica geral do perfil, leve predominância de pessoas do gênero feminino (54,55\%), a maioria dos respondentes estão na faixa entre 26 e 35 anos e residem no interior do Rio Grande do Sul. Quanto ao nível de escolaridade, a maioria possui o ensino superior incompleto, mais da metade dos respondentes não exerce cargo de gestão atualmente e o setor de serviços é a área de atuação da maior parte da amostra.

Após a caracterização, buscou-se analisar a incidência de níveis de inteligência emocional na amostra, sendo possível verificar que a amostra pesquisada possui um sentimento de inteligência emocional médio e alto, considerando suas cinco dimensões, $77,27 \%$ da amostra estão com altos níveis gerais de inteligência emocional e 22,73\% apresentam médios índices de inteligência emocional no ambiente de trabalho, deste modo pode-se considerar que a maioria dos respondentes em questão apresenta altos índices de inteligência emocional.

Na sequência buscou-se analisar a incidência de níveis de engajamento no trabalho. Neste quesito a amostra apresentou indicativos de engajamento positivos, sendo que $67,33 \%$ da amostra estão com altos níveis de engajamento no ambiente de trabalho, 30,33\% apresentam médios índices de engajamento e, apenas 2,34\% podem ser considerados não engajados. De acordo com Schaufeli e Bakker (2003) quanto mais alto o escore identificado em vigor, dedicação e absorção, maior será o engajamento no trabalho, sendo assim considera-se que a amostra em questão apresenta altos índices de engajamento.

No que se refere a questão de estudo, tratando das relações entre as dimensões de inteligência emocional e de Engajamento no trabalho dos gestores e membros de equipes é possivel afirmar que há uma forte correlação positiva entre a automotivação e dedicação RGO REVISTA GESTÃO ORGANIZACIONAL | VOL 11 - № 1 - JAN./ABR. - 2018 
$(0,61198)$, automotivação e o engajamento $(0,61918)$ e entre a inteligência emocional e a dedicação $(0,61134)$. Desta forma pode-se afirmar que indivíduos que enfrentam qualquer situação independente da dificuldade que esta apresenta (automotivação), consegue também se manter envolvido em seu trabalho e experienciar um senso de significância, sentindo-se conectadas ao trabalho e entusiasmadas com suas tarefas (dedicação)

Em resposta ao objetivo geral, pode afirmar-se que, existe relação entre a inteligência emocional e o engajamento no trabalho $(0,61309)$ e esta relação é forte e positiva, ou seja, quanto mais índices de inteligência emocional o profissional apresentar, maior será o seu engajamento em relação ao seu trabalho.

Mesmo com os resultados encontrados, onde a maioria em questão apresenta altos níveis de inteligência emocional e engajamento, as avaliações foram realizadas a partir de um auto relato, ou seja, a partir do sentimento de ter ou não a habilidade pesquisada. $\mathrm{A}$ escassez de estudos e instrumentos de mensuração sobre inteligência emocional, principalmente pelo ponto de vista de gestão e liderança foi a maior limitação da pesquisa, sendo que, apesar de ser um estudo quantitativo, a generalização dos resultados não pode ser estendida aos demais profissionais do estado ou mesmo do Brasil, em função das diferenças peculiares de cada população, assim como da estrutura e cultura das organizações.

Como sugestão de estudos futuros, indica-se a replicação desse estudo em outros contextos e realidades organizacionais, inclusive em amostras específicas de mulheres para buscar-se entender os motivos das diferenças entre os gêneros e os fenômenos estudados. As abordagens da inteligência emocional nos espaços organizacionais podem ser usadas como alavanca para estimular uma forma construtiva de repensar a gestão e a relação entre as equipes, elevando os efeitos da positividade organizacional, gerando impactos positivos e engajamento em altos níveis no ambiente de trabalho. $O$ desenvolvimento de novas culturas organizacionais que foquem nas forças a partir do potencial humano, promove maior coesão das equipas e bem-estar de todos os envolvidos nos processos empresariais, gerando resultados para as organizações.

Os resultados obtidos neste estudo sinalizam fortemente à uma pratica de gestão voltada aos potenciais de recursos humanos das empresas, que por sua vez precisam receber mais investimentos (de tempo e financeiro) nas questões que potencializem a discussão e o desenvolvimento dos indivíduos através da inteligência emocional, gerando um diferencial competitivo através do engajamento dos gestores e consequentemente de suas equipes.

\section{REFERENCIAS BIBLIOGRÁFICAS}

AZEVEDO, Alzira. O poder transformador da empatia nas relações humanas. VOCÊ S/A, Rio de Janeiro - maio. 2016. Disponível em: < http://vocesa.uol.com.br/noticias/mercado/opoder-transformador-da-empatia-nas-relacoes-humanas.phtml\#.V-3FrogrLDc>. Acesso em: 29 set. 2016.

BAKKER, A. B, DEMEROUTI, E., HAKANEN, J.J., e XANTHOPOULOU, D. Job Resources Boost Work Engagement, particularly when job demands are high. Washington: Journal of educational Psychology, 99, 274-284. 2007.

BAKKER, A. B., ALBRECHT, S. L., LEITER, M. P. Key questions regarding work engagement. European Journal of Work and Organizational Psychology, 20(1), 4-28, 2011.

BAKKER, A. B., Albrecht, S. L., Leiter, M. P. Work engagement: further reflections on the state of play. European Journal of Work and Organizational Psychology, 20(1), 74-88, 2011. 
BAKKER, A. B., DEMEROUTI, E. Towards a model of work engagement. Career Development International, 13(3), 209-233, 2008.

BRADBERRY, Travis, GREAVES Jean. Inteligência Emocional 2.0 - São Paulo: HSM Editora, 2016

BRANCO, M. A. Da Veiga. Auto-Motivação, Coimbra (Pt): Quarteto Editora, 2004

BRACKETT, M. A., MAYER, J. D. (2003). Convergent, discriminant, and incremental Validity of Competing Measures of Emotional Intelligence. Personality and Social Psychology Bulletin, 9, 1147-1158.

CHERNISS, C. (2002). Competência social e emocional no local de trabalho. Em R. Bar-On J. D. A. Parker (Orgs.). Manual de inteligência emocional (pp. 315-328). Porto Alegre: Artmed.

DAVIDSON, Richard J. O estilo emocional do cérebro; Rio de Janeiro: Sextante, 2013.

DEL PRETTE, A e DEL PRETTE, Z.A.P. Psicologia das Relações Interpessoais: vivências para o trabalho em grupo. Petrópolis: Ed. Vozes, 2001.

FIELD, Andy. Discovering Statitics Using Sps. Third Edition. Sage, 2009.

GOLEMAN, Daniel, ph.D. Trabalhando com a inteligência emocional, Rio de Janeiro - Editora Objetiva, 1999.

GOLEMAN, Daniel, ph.D. A inteligência emocional: a teoria revolucionaria que define o que é ser inteligente. Rio de Janeiro - Ed. Objetiva, 1995.

GOLEMAN, Daniel, ph.D. O Poder da Inteligência emocional / Daniel Goleman, Richard Boyatzis, Annie Mckee; tradução de Cristina Serra. - Rio de Janeiro: campus, 2002.

GOLEMAN, Daniel, ph.D. A inteligência emocional: a teoria revolucionaria que define o que é ser inteligente. Rio de Janeiro - Ed. Objetiva, 2012.

GOLEMAN, Daniel, ph.D. A inteligência emocional na formação do líder de sucesso. Rio de Janeiro - Ed. Objetiva, 1ed, 2015.

GOLEMAN, Daniel; BOYATZIS, Richard; MCKEE, Annie. O poder da inteligência emocional. Rio de Janeiro: Campus, 2002.

GONZALES-ROMA, Vicente, SCHAUFELI, Wilmar B., BAKKER, Arnold B., LLORET, Susana. Burnout and work engagement: Independent factors or opposite poles? Journal of Vocational Behavior 68, p.165-174, 2006.

HALLBERG, U. E.; SCHAUFELI, W. B. "Same same" but different? Can work engagement be discriminated from job involvement and organizational commitment? European Psychologist, v. 11, n. 2, p. 119-127, 2006.

KAHN, W. A. Psychological conditions of personal engagement and disengagement at work. Academy of Management Journal, v. 33, n. 4, p. 692-724, 1990.

KRZNARIC, Roman. $O$ poder da empatia: a arte de se colocar no lugar do outro para transformar o mundo - tradução Maria Luiza X. de A. Borges. - 1a .ed. - Rio de Janeiro: Zahar, 2015.

LOPES, Luis Felipe Dias. Métodos Quantitativos. 1a edição, Universidade Federal de Santa Maria - UFSM, 2016.

LUTHANS, F., \& YOUSSEF, C. M. Emerging positive organizational behavior. Journal of Management 33, 321-349, 2007.

MAYER, J. D. \& Salovey, P. (1997). What is emotional intelligence? Em P. Salovey \& D. J. Sluyter (Orgs.), Emotional development and emotional intelligence: Implications for Educators (pp. 3-31). New York: Basic Books.

MENDENHALL, William. Probabilidade e estatística. Traduzido por: José Fabiano da Rocha. Rio de Janeiro: Campus, 1985. 
MERSINO, Anthony C. Inteligência emocional para gerenciamento de projetos. São Paulo: M.Books do Brasil, 2009.

PARODI, Karin. Engajamento: o grande desafio das organizações, 2015. Disponível em:< http://hbrbr.com.br/engajamento-o-grande-desafio-das-organizacoes/ >. Acesso em: 09 de Out. 2016.

PORTELLA, M.; STINGEL, A.; BASTOS, M. C. Curso de Formação em terapia CognitivoComportamental. Apostila para consulta. Rio de Janeiro, 2005.

RAIOL, Sérgio Luiz da Silva. Inteligência Emocional no Trabalho. Montevideo (Uy), 2008. Disponível em <http://www.fabelnet.com.br/unempe2/ver artigo.php?artigo id=48> Acesso em: 26 setembro 2016.

Roberts, R. D.; Flores-Mendoza, C. E., \& Nascimento, E. (2002). Inteligência Emocional: Um Construto Científico? Cadernos de Psicologia e Educação Paidéia, 12 (23), 77-92.

ROGERS, C. R.; KINGET, G. M. Psicoterapia e Relações Humanas, v. 1, Belo Horizonte Editora Interlivros, 1977.

SALANOVA, M.; SCHAUFELI, W. B. El. Engagement en el trabajo. Madrid: Alianza Editorial, 2009.

Salovey, P. \& Mayer, J. D. (1990). Emotional Intelligence Imagination. Cognition and Personality, 9, 185-211.

SCHAUFELI, W. B.; BAKKER, A. B. Job demands, job resourcesand their relationship with burnout and engagement: a multisample study.Journal of Organizational Behavior, v.25, p.293-315, 2004.

SCHAUFELI, Wilmar; DIJKSTRA, Pieternel; VASQUEZ, Ana C. O engajamento no Trabalho São Paulo - Editora Casapsi - 2013.

SHAUFELI, Wilmar; BAKKER, Arnold. UWES- Utrecht Work Engagement Scale Preliminary Manual.Occupational. Health Psychology Unit Utrecht University, 2003. Adaptado e traduzido por: ANGST, Rosana, BENEVIDES-PEREIRA, Ana Maria T., PORTO-MARTINS, Paulo C. Escala de Engagement do Trabalho de Utrecht, 2009.

SELIGMAN, M. E. P. \& Csikszentmihalyi, M. (2001). Positive psychology: an introduction. American Psychologist, 55(1), 5-14. 